\title{
PRODUÇÃO DE CELULASES ESTÁVEIS A TEMPERATURA E PH A PẢRTIR DA FERMENTAÇÃO EM ESTADO SOLIDO DA PALMA FORRAGEIRA
}

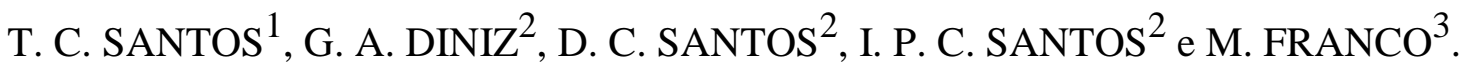 \\ ${ }^{1}$ Universidade Federal do Rio de Janeiro, Departamento de Engenharia Bioquímica ${ }^{2}$ Universidade \\ Estadual do Sudoeste da Bahia, Departamento de Estudos Básicos e Instrumentais ${ }^{3}$ Universidade \\ Estadual de Santa Cruz, Departamento de Ciências Exatas e Tecnológicas. \\ E-mail para contato: tcsantos@ufrj.br
}

\begin{abstract}
RESUMO - Objetivou-se avaliar a utilização da palma forrageira como substrato para a produção de enzimas celulolíticas, através da fermentação em estado sólido com o auxílio do fungo filamentoso Rhizopus sp. A palma foi desidratada até atingir aproximadamente $2 \%$ de umidade. As variáveis avaliadas no processo fermentativo foram, a atividade de água, tempo de fermentação e atividade de água, para adequação dos modelos lineares de segunda ordem para a estimativa de superfícies de respostas. Os tempos ótimos para as enzimas produzidas pelo Rhizopus sp. foram em $68,12 \mathrm{~h}$ para a produção de endoglucanase com 7,859 U/mL e 72,48 h para celulases totais com 13,571 U/mL. As enzimas demostraram grande tolerância a exposição em uma ampla faixa de temperatura $\left(0\right.$ a $\left.80^{\circ} \mathrm{C}\right)$ e $\mathrm{pH}(3$ a 9$)$ a cerca de 150 minutos com atividade relativa superior a $50 \%$ para todas as enzimas em ambas as análises. O complexo celulásico não sofre desativação considerável se armazenado congelado na temperatura de $-18^{\circ} \mathrm{C}$ até 144 horas.
\end{abstract}

\section{INTRODUÇÃO}

A palma (Nopalea coccinellifera) é uma cactácea de origem mexicana, rústica, resistente e adaptada a regiões secas. No semiárido brasileiro, essa forrageira é aplicada nos diversos sistemas de produção pecuário, no entanto, é uma planta de enorme potencial produtivo e de múltiplas utilidades, podendo ser usada na alimentação humana, na produção de medicamentos, cosméticos e corantes, na conservação e recuperação de solos, como cercas vivas e paisagismo. A composição química relativa possui alto valor de nutrientes digestíveis totais. Os níveis de carboidratos solúveis também são elevados, bem como os teores de cinza, vitaminas e ferro, devendo serem destacados os teores de cálcio (3\%); potássio (2,5\%) e fósforo $(0,15 \%)$ (CHIACCHIO et al. 2006), além de baixos teores de matéria seca $(11,69 \pm 2,56 \%)$, proteína bruta $(4,81 \pm 1,16 \%)$, fibra em detergente neutro $(26,79 \pm$ $5,07 \%)$ e fibra em detergente ácido (18,85 $\pm 3,17 \%)$ (SANTOS et al., 2011a).

Essa planta é resistente à seca, sobrevivendo com pluviosidade mínima, estando amplamente difundida na região semiárida da Bahia, onde residem $48 \%$ da população estadual. O semiárido é caracterizado por solos rasos, pedregosos ou arenosos e com pouca matéria orgânica. As precipitações 
pluviométricas são irregulares e sua cobertura vegetal é constituída por plantas que suportam longos períodos de estiagem (CHIACCHIO et al., 2006). Devido à sua composição essa biomassa vegetal apresenta potencial biotecnológico para a produção de compostos de interesse industrial como bioetanol, glicose, proteínas, enzimas e compostos de aroma, entre outros (SOCCOL et al., 2010).

Dentre esses biocompostos, as enzimas são aplicadas em diversos processos industriais. Esse setor apresenta muitas iniciativas de pesquisa e desenvolvimento, resultando na elaboração de diversos produtos, além de melhoramento dos processos e do desempenho já existentes no mercado. No entanto, o custo dessas enzimas é o que limita sua aplicação em grande escala. Reduzir os custos de produção é fundamental para extender essa aplicação (PARK et al., 2005). Nesse sentido, estudar a aplicação da palma forrageira como matéria prima para bioprocessos, pode viabilizar a aplicação na produção de biocompositos (GHORAI et al., 2009). O mercado global de enzimas movimentou aproximadamente US\$ 5,1 bilhões em 2008 e a projeção estimada em 2013 foi de US\$ 7 bilhões. As pesquisas envolvem a otimização do processo e a produção de enzimas com potencial industrial visando à diversificação do comércio mundial (MENDES et al., 2011).

Objetivou-se investigar a utilização da palma forrageira (Nopalea cochenillifera) como matéria prima para a produção de enzimas celulolíticas através do processo de fermentação em estado sólido (FES) com o fungo fillamentoso Rhizopus sp.

\section{MATERIAIS E METODOS}

\subsection{Material}

A palma forrageira foi coletada no campo Agrostológico da Universidade Estadual do Sudoeste da Bahia - Campus de Itapetinga. Após a higienização e corte foi seca em estufa de secagem (SOLAB SL 102, Piracicaba-SP, Brasil) a $65{ }^{\circ} \mathrm{C}$ por 24 horas e trituradas em moinho tipo Willey (ACB LABOR, São Paulo-SP, Brasil) a uma granulométrica aproximada de $2 \mathrm{~mm}$, assim como descrito por Santos et al. (2011a). O microrganismo utilizado para a fermentação foram utilizados o Rhizopus $s p$. proveniente do Laboratório de Aproveitamento de Resíduos Agroindustriais da UESB campus de Itapetinga. A cultura esporulada (em PDA HIMEDIA acidificado a pH 5,2 e inclinado) foi suspensa em solução de Tween 80 (VETEC) a 0,01\% procedendo-se a contagem do número de esporos em suspensão, utilizando câmara de neubauer dupla espelhada e microscopio binocular (SANTOS et al., 2011b).

\subsection{Condições experimentais e Métodos Analíticos}

Os ensaios foram realizados em erlenmeyers contendo $10 \mathrm{~g}$ de farelo de palma. Os cultivos foram conduzidos em estufa bacteriológica refrigerada com ventilação forçada (SOLAB SL 222/CFR Piracicaba, SP - Brazil). Após o processo fermentativo, a extração realizada foi mecânica (filtração por pressão) do extrato enzimático com solução tampão de citrato de sódio (SIGMA) com o pH 4,8 a $50 \mathrm{mM}$, o extrato enzimático proveniente da fermentação foi recolhido e centrifugado a $1000 \mathrm{rpm}$ por 10 minutos em centrifuga refrigerada a $4{ }^{\circ} \mathrm{C}$ (CIENTEC CT - 6000R Piracicaba, SP - Brazil).

\subsection{Quantificação da enzima Endoglucanase}


Para a atividade de endoglucanse, o método escolhido se baseia na dosagem de açúcares redutores produzidos pela degradação de carboximetilcelulose (CMC - QUIMICS) a $2 \%$ (p/v) diluído previamente na solução citrato de sódio (QUIMICS) com o pH 4,8 a $50 \mathrm{mM}$, utilizando-se para tal o método do ácido dinitrosalicílico (DNS - SIGMA) (MILLER, 1959). Onde para os tubos contendo os ensaios reacionais foram adicionados $0,5 \mathrm{~mL}$ de solução tampão de citrato de sódio com o pH 4,8 a 50 $\mathrm{mM}, 0,5 \mathrm{~mL}$ de extrato enzimático e $0,5 \mathrm{~mL}$ de CMC, o controle na reação foram adicionados $0,5 \mathrm{~mL}$ da mesma solução tampão e $0,5 \mathrm{~mL}$ de extrato enzimático. O branco da analise continha $0,5 \mathrm{~mL}$ de DNS e 0,5 mL de solução tampão. As amostras foram incubadas em estufa bacteriológica (SOLAB SL 222/CFR Piracicaba - SP - Brazil) a $50{ }^{\circ} \mathrm{C}$ por 10 minutos, a reação foi interrompida com a adição de $0,5 \mathrm{~mL}$ de DNS. Os tubos foram submergidos a água fervente por 5 minutos, logo após foram adicionados $6,5 \mathrm{~mL}$ de água destilada para posterior medição de absorbância na faixa de $540 \mathrm{~nm}$ realizada em espectrofotômetro (BEL PHOTONICS SF200DM - UV Vis - $1000 \mathrm{~nm}$, Osasco - SP Brazil). (GHOSE, 1987).

\subsection{Quantificação do complexo Celulases Totais (exoglucanases e endoglucanases)}

A atividade de celulases totais foi determinada através da dosagem, pelo método do DNS, também através dos açúcares redutores liberados durante a degradação de uma tira de papel de filtro Whatman $\mathrm{n}^{\circ} 1$ medindo $1,0 \mathrm{~cm} \times 6,0 \mathrm{~cm}$. Para os tubos contendo os ensaios reacionais foram adicionados 1,0 mL de solução tampão de citrato de sódio com o pH 4,8 a $50 \mathrm{mM}, 0,5 \mathrm{~mL}$ de extrato enzimático e uma tira de papel filtro. Para o controle na reação foram adicionados $1 \mathrm{~mL}$ da mesma solução tampão e $0,5 \mathrm{~mL}$ de extrato enzimático, o controle do substrato foram adicionados $1,5 \mathrm{ml}$ de solução tampão e uma tira de papel filtro (GHOSE, 1987). As amostras foram incubadas em estufa bacteriológica (SOLAB SL 222/CFR Piracicaba - SP - Brazil) a $50{ }^{\circ} \mathrm{C}$ por 60 minutos, a reação foi interrompida com a adição de $3 \mathrm{~mL}$ de DNS. Os tubos foram submergidos a água fervente por 5 minutos, logo após foram adicionados $20 \mathrm{~mL}$ de água destilada para posterior medição de absorbância na faixa de $540 \mathrm{~nm}$ realizada em espectrofotômetro (BEL PHOTONICS SF200DM - UV Vis - 1000 nm, Osasco - SP - Brazil). (GHOSE, 1987).

\subsection{Cálculo das atividades enzimáticas celulolíticas}

A curva padrão para a endoglacanase e celulases totais foi determinada a partir da determinação de glicose (SIGMA) nas concentrações de 0,1 a 2,0 g/L pelo método do DNS (MILLER, 1959) com posterior medição de absorbância na faixa de $540 \mathrm{~nm}$ realizada em espectrofotômetro (BEL PHOTONICS SF200DM - UV Vis - 1000 nm, Osasco - SP - Brazil). (GHOSE, 1987).

\subsection{Ensaios de termoestabilidade}

Com o objetivo de se determinar a estabilidade térmica das enzimas produzidas, os extratos enzimáticos foram submetidos às temperaturas de $20^{\circ} \mathrm{C}$ a $100^{\circ} \mathrm{C}$, com intervalos de $10^{\circ} \mathrm{C}$ durante 0 a 240 minutos. Após o tempo de reação, os tubos foram colocados em banho de gelo por 5 minutos para encerrar a reação de hidrólise enzimática e seguiu a determinação das atividades enzimáticas conforme descrito anteriormente.

\subsection{Ensaios de estabilidade ao $\mathrm{pH}$}


A estabilidade ao $\mathrm{pH}$ foi determinada por incubação, retirando-se alíquotas durante 0 a 240 minutos incubação nos pHs: 3, 4, 5, 6, 7 e 8 em tampão citrato de sódio. A atividade de cada enzima foi avaliada de acordo com a otimização da metodologia de superfície de resposta em três repetições experimentais conforme descrito anteriormente.

\subsection{Análises estatísticas}

O planejamento fatorial $2^{3-1}$ fracionado constituiu, em dois níveis $(-1$ e +1$)$, envolvendo as variáveis independentes citadas, contou ainda com 4 repetições no pontos centrais (nível zero) para o cálculo de resíduos e erro padrão, a partir da verificação dos resultados foram aplicados na metodologia de Superfície de Resposta (SR) e do Delineamento de Box e Behnken (DBB). Assim, o planejamento fatorial consistiu em 18 ensaios e os valores das variáveis estudadas estão descritos na Tabela 1 .

Tabela 1: Valores codificados e valores reais para cada fator em estudo Fatorial em valores codificados

Fatorial em valores reais

$\begin{array}{ccccccc}\text { Ensaio } & \left(\mathrm{X}_{1}, \mathrm{~h}\right) & \left(\mathrm{X}_{2}, \mathrm{aw}\right) & \left(\mathrm{X}_{3},{ }^{\circ} \mathrm{C}\right) & \left(\mathrm{X}_{1}, \mathrm{~h}\right) & \left(\mathrm{X}_{2}, \mathrm{aw}\right) & \left(\mathrm{X}_{3},{ }^{\circ} \mathrm{C}\right) \\ 1 & -1 & -1 & -1 & 24 & 0.786 & 25 \\ 2 & -1 & -1 & +1 & 24 & 0.786 & 35 \\ 3 & +1 & -1 & -1 & 120 & 0.786 & 25 \\ 4 & +1 & -1 & +1 & 120 & 0.786 & 35 \\ 5 & -1 & +1 & -1 & 24 & 0.903 & 25 \\ 6 & -1 & +1 & +1 & 24 & 0.903 & 35 \\ 7 & +1 & +1 & -1 & 120 & 0.903 & 25 \\ 8 & +1 & +1 & +1 & 120 & 0.903 & 35 \\ 9 & 0 & -1 & 0 & 72 & 0.786 & 30 \\ 10 & 0 & +1 & 0 & 72 & 0.903 & 30 \\ 11 & -1 & 0 & 0 & 24 & 0.865 & 30 \\ 12 & +1 & 0 & 0 & 120 & 0.865 & 30 \\ 13 & 0 & 0 & -1 & 72 & 0.865 & 25 \\ 14 & 0 & 0 & +1 & 72 & 0.865 & 35 \\ 15 & 0 & 0 & 0 & 72 & 0.865 & 30 \\ 16 & 0 & 0 & 0 & 72 & 0.865 & 30 \\ 17 & 0 & 0 & 0 & 72 & 0.865 & 30 \\ 18 & 0 & 0 & 0 & 72 & 0.865 & 30\end{array}$

* Matriz do planejamento experimental.

A análise de variância (ANOVA) para os modelos foi realizada e a importância do modelo foi examinada pelo teste estatístico de Fisher (teste F) através do teste de diferenças significativas entre as fontes de variação nos resultados experimentais, ou seja, a significância da regressão (SOR), a falta de ajuste, e o coeficiente de determinação múltipla $\left(\mathrm{R}^{2}\right)$. Em primeiro 
lugar, os resultados obtidos a partir de experiências foram submetidos a análise de variância ANOVA, e os efeitos foram considerados significativos quando $p<0,01$. Com um modelo polinomial de segunda ordem (Eq. (1)), dados experimentais e de regressão coeficiente foram ajustadas e coeficientes de regressão foram obtidos por regressão linear múltipla, onde bo, bi, $b_{\mathrm{ii}}$, $\mathrm{b}_{\mathrm{ij}}$, e $\mathrm{b}_{\mathrm{ijk}}$ representar todo o processo constante efeito, os efeitos linear e quadrático de Xi, e o efeito de interação entre $\mathrm{X}_{\mathrm{i}}$ e $\mathrm{X}_{\mathrm{j}}, \mathrm{X}_{\mathrm{i}}, \mathrm{X}_{\mathrm{j}}$ e $\mathrm{X}_{\mathrm{k}}$ sobre a atividade enzimática, respectivamente.

$$
E A=\beta_{o}+\sum \beta_{i} X_{i}+\sum \beta_{i i} X_{i}^{2}+\sum \beta_{i j} X_{i} X_{j}+\sum \beta_{i j} X_{i} X_{j} X_{k}
$$

O software estatístico utilizado foi o Statistical Analysis System ${ }^{\circledR}($ SAS) versão 9.3, para elaboração dos gráficos foi utilizado o software Sigma Plot ${ }^{\circledR}$ versão 11.0.

\section{RESULTADOS E DISCUSSÃO}

Os resultados experimentais para a atividade enzimática nas condições de atividade de água e tempo estudadas foram submetidos a ANOVA (Tabela 2) e análise de regressão.

Tabela 2. Ajuste de dados obtidos a partir da ANOVA para o modelos de superfície de respostas quadráticas.

$\begin{array}{llllll} & \text { GL } & \text { SQ } & \text { MS } & \text { F } & P \\ \text { Endoglucanase } & & & & & \\ \text { Modelo } & 4 & 55,45346 & 13.86336 & 10,19 & 0,0006 \\ \text { Erro } & 13 & 17,68501 & 1.36039 & & \\ \text { Falta de ajuste } & 14 & 73,05206400 & 5,21800457 & 181,18 & \\ \text { Erro puro } & 3 & 0,08640000 & 0,02880000 & & \\ \text { Total } & 17 & 73,13846 & & & \\ \mathrm{R}^{2} & 0,7582 & & & & \\ \text { Celulases Totais } & & & & & \\ \text { Modelo } & 4 & 207,97351 & 51,99338 & 1,61754 & <0,0001 \\ \text { Erro } & 13 & 21,02796 & 1,61754 & & \\ \text { Falta de ajuste } & 14 & 228,974976 & 16,3553554 & 1851,83 & \\ \text { Erro puro } & 3 & 0,026496 & 0,0088320 & & \\ \text { Total } & 17 & 229,00147 & & & \\ & & & & & \\ \mathrm{R}^{2} & 0,9082 & & & & \end{array}$

O comportamento dos sistemas estudados pode ser descrito por um modelo polinomial de segunda ordem, onde o termo de interação entre as variáveis independentes foi não significativo ( $\mathrm{p}>0,01)$. Os modelos reduzidos podem ser descritos por equações $(2-3)$, em termos de valores não codificados.

Eq.2 $-4,436+0,101 X_{1}-0,0007 X_{1}^{2}+0,290 X_{3}+0,291 X^{2}$ 


$$
\begin{gathered}
\text { Eq.3 }-3082,322+0,326 X_{1}+7038,565 X_{2}+8,481 X_{3}-0,00240 X_{1}^{2}-4163,338 \\
X_{2}^{2}-0,142 X_{3}^{2}
\end{gathered}
$$

A otimização do tempo foi de 68,12 h para a produção de endoglucanase com 7,859 $\mathrm{U} / \mathrm{mL}$ e $72,48 \mathrm{~h}$ para celulases totais com $13,571 \mathrm{U} / \mathrm{mL}$.
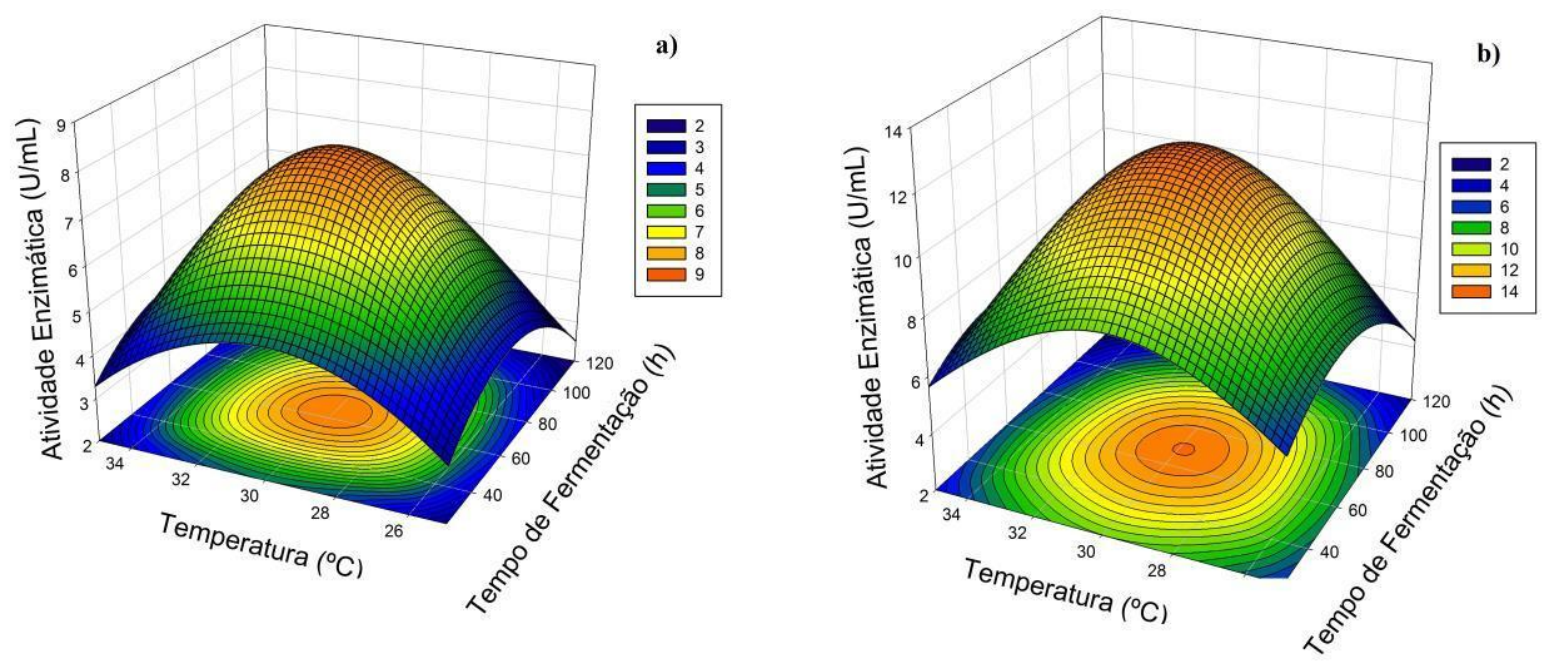

Figura 2. Superfície de resposta das atividades enzimáticas em função do tempo de fermentação e temperatura: a) endoglucanase, b) celulases totais.

A produção das enzimas observadas as somente o complexo celulases totais que foi verificado a otimização em relação a atividade de agua em 0,875 aw. As melhores atividades enzimáticas foram encontradas em $30,41{ }^{\circ} \mathrm{C}$ para a produção de endoglucanase e $27,86{ }^{\circ} \mathrm{C}$ para celulases totais.

Nas enzimas avaliadas neste trabalho (Figura 3.) todas permaneceram com pelo menos $75 \%$ de atividade relativa quando submetidas a $60^{\circ} \mathrm{C}$ por $140 \mathrm{~min}$, com destaque para a enzima endoglucanase que permaneceu $85 \%$ ativa a $80{ }^{\circ} \mathrm{C}$ depois de 240 minutos de exposição. Em relação a estabilidade ao $\mathrm{pH}$ (Figura 3), as enzimas demostraram atividade relativa superior a $90 \%$ em pHs quantificados a 5 e 6 durante 240 minutos, as enzimas permaneceram ativas com $50 \%$ de atividade relativa durante 180 minutos nas demais faixas de $\mathrm{pH}$ (3 a 8), o que denota estabilidade estrutural e atividade ácido-alcalino-tolerante, que habilita utilização destas em diferentes processos industriais. 


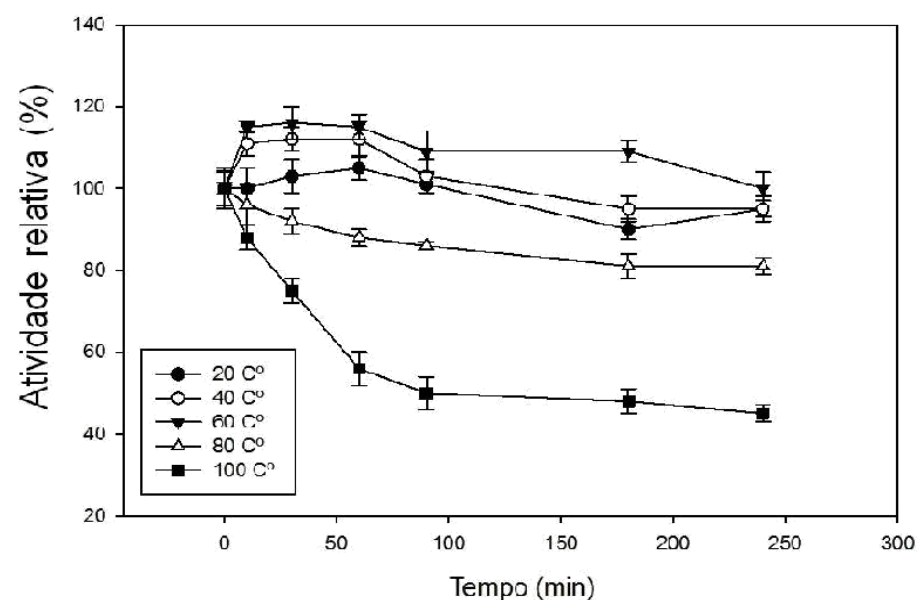

a)

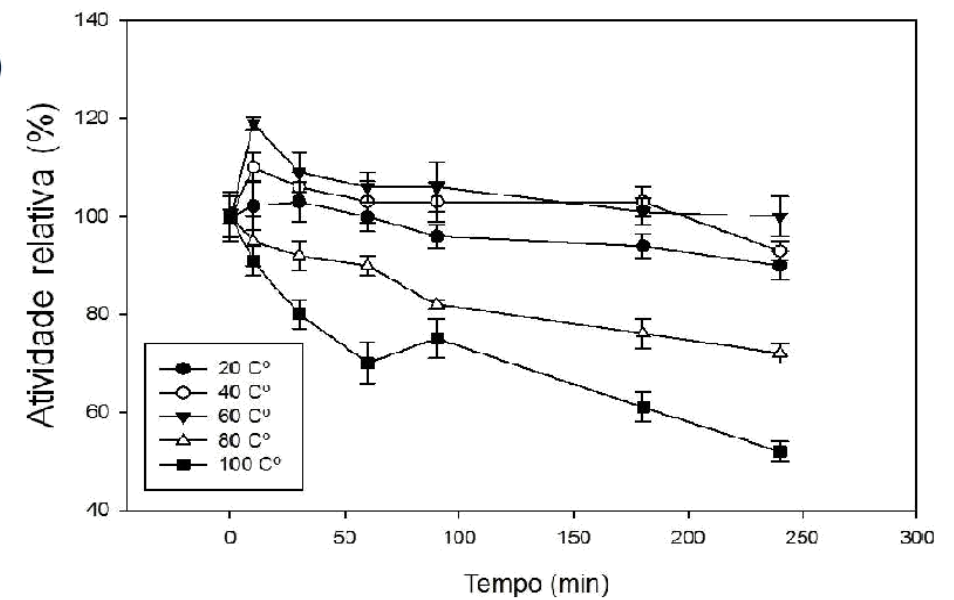

b)

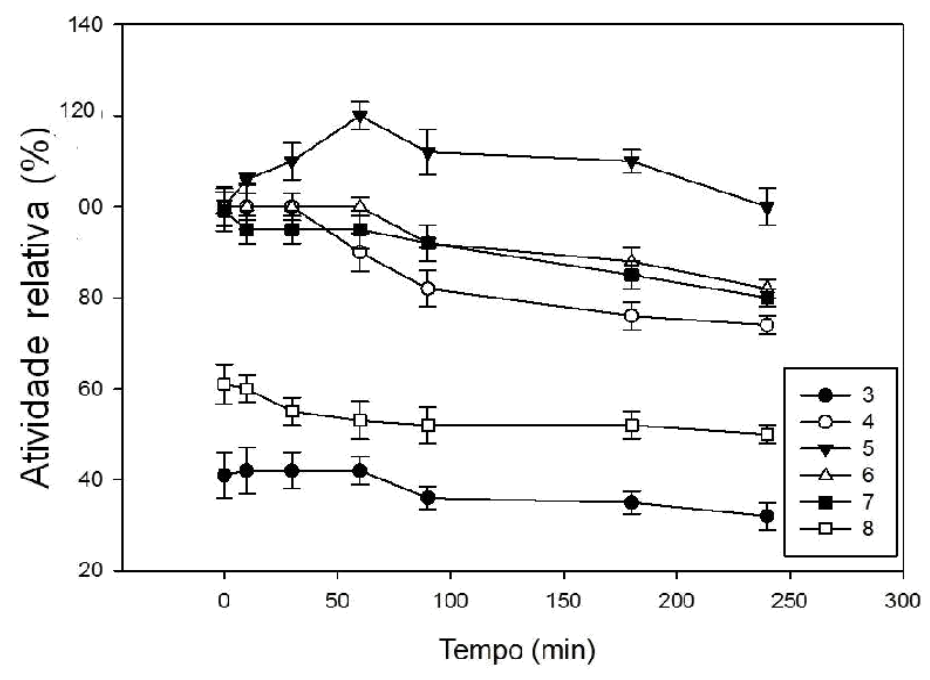

c)

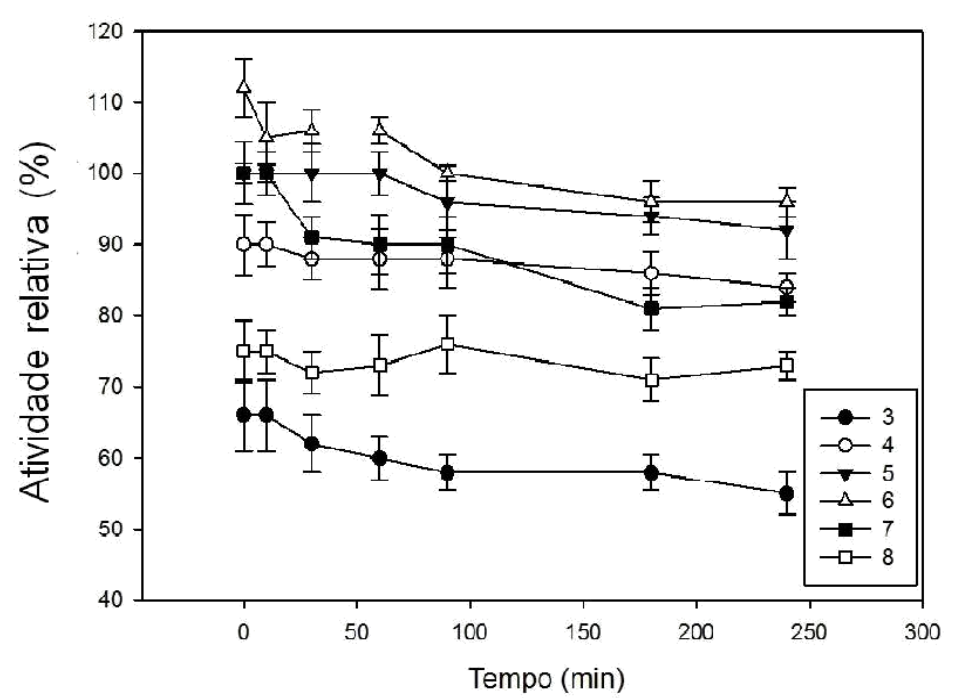

Figura 3. Termoestabilidade enzimática: a) endoglucanase, b) celulases totais. Estabilidade ao $\mathrm{pH}$ c) endoglucanase, d) celulases totais. 


\section{4 - CONCLUSÃO}

Os resultados indicam que o Rhizopus sp. é bastante promissor, no que se diz respeito à obtenção de enzimas celulásicas com a fermentação em estado solido da palma forrageira. As enzimas demostraram grande tolerância a exposição em uma ampla faixa de temperatura e pH a cerca de 150 minutos com atividade relativa superior a 50\%, para todas as enzimas em ambas as análises, o que indica grande relevância em aplicações industriais.

\section{REFERÊNCIAS}

CHIACCHIO, F. B.; MESQUITA, A. S.; SANTOS, J. R. Palma forrageira: uma oportunidade econômica ainda desperdiçada para o semi-árido baiano. Bahia Agrícola, v.7, n.3, p.39-49, 2006.

GHOSE T. K. Measurement of cellulase activities. Pure \& Applied Chemistry, v.59, p.257-268, 1987.

MENDES, A. A.; OliVEIRA, P. C.; CASTRO, H. F.; GIORDANO, R. L. C. Aplicação de Quitosana como suporte para a imobilização de enzimas de interesse industrial. Química Nova, v.34 n.5, p.831-840, 2011.

MILLER, G.L. Use of dinitrosalicylic acid reagent for determination of reducing sugar. Analytical Chemistry, v. 31, p. 426-428, 1959.

SANTOS, T. C.; ABREU FILHO, G.; ROCHA, T. J. O.; FRANCO, M. Aplicação da fermentação em estado sólido sobre o farelo de cacau (Theobroma Cacao L.): Obtenção de ligninases. Semina: Ciências Exatas e Tecnológicas, v.32, p.87-96, 2011 a.

SANTOS, T. C.; CAVALCANTI, I. S.; BONOMO, R. C. F.; SANTANA, N. B.; FRANCO, M. Optimization of productions of cellulolytic enzymes by Aspergillus niger using residue of mango a substrate. Ciência Rural (UFSM. Impresso), v. 41, p. 2210-2216, 2011 b.

SOCCOL, C. R.; VANDENBERGHE, L. P. S.; MEDEIROS, A. B. P.; KARP, S. G.; BUCKERIDGE, M.; RAMOS, L. P.; PITARELO, A. P.; FERREIRA-LEITÃO, V.; GOTTSCHALK, L. M. F.; FERRARA, M. A.; BON, E. P. S.; MORAES, L. M. P.; ARAÚJO, J. A.; TORRES, F. A. G. Bioethanol from lignocelluloses: Status and perspectives in Brazil. Bioresource Technology, v.101, p.4820-4825, 2010. 